\title{
A decision support system to assist river basin hydroelectric inventory studies in Brazil
}

\author{
F. S. Costa ${ }^{1,2}$, I. P. Raupp ${ }^{1}$, J. M. Damázio ${ }^{1,2}$, S. H. M. Pires ${ }^{1}$, \\ K. Garcia ${ }^{1}$, D. F. Matos ${ }^{1}$, P. C. Menezes ${ }^{1}$, A. M. Mollica ${ }^{1}$ \\ \& L. R. Paz \\ ${ }^{I}$ Department of Energy Optimization and Environment, \\ Electric Power Research Center-CEPEL, Brazil \\ ${ }^{2}$ Rio de Janeiro State University - UERJ, Brazil
}

\begin{abstract}
The large hydroelectric potential of Brazilian river basins is being progressively exploited, and today, this type of electricity generation represents $86 \%$ of the Brazilian electric power matrix. The hydroelectric expansion planning in Brazil is done through a serie of studies and the Hydropower Inventory Studies is one of the earliest stages of this process. So, that is the moment when every option for the division of the water head in the river basins should be studied in order to select the one that gives the best energetic, economic, social and environmental balance, according to the Hydroelectric River Basin Inventory's Manual. To assist Hydroelectric Inventory Studies a computerized decision support system, called SINV, has been developed and it integrates data management with simulation/optimization and plotting tools to aid in energetic and socioenvironmental comparisons of the different head division schemes considering a multi-objective criterion. This paper presents a river basin inventory study case using the SINV package.
\end{abstract}

Keywords: hydropower inventory, socio-environmental impacts, hydroelectric expansion planning, multi-objective criterion, decision support system.

\section{Introduction}

The large hydroelectric potential of Brazilian river basins ( $\cong 250.000 \mathrm{MW}$ ) has being progressively exploited since the beginning of the last century, and today, 
with $30 \%$ of the potential already exploited, this type of electricity generation represents $86 \%$ of the Brazilian electric power matrix, with more than 120 hydro plants with capacity greater than $30 \mathrm{MW}$ in operation. The hydroelectric expansion planning in Brazil is done through a series of studies that considers different time horizons and successive approximations [1]. The Hydropower Inventory Studies is one of the earliest stages of this process. It comes after river basin recognition studies and is requested by long term planning studies as shown in Figure 1.

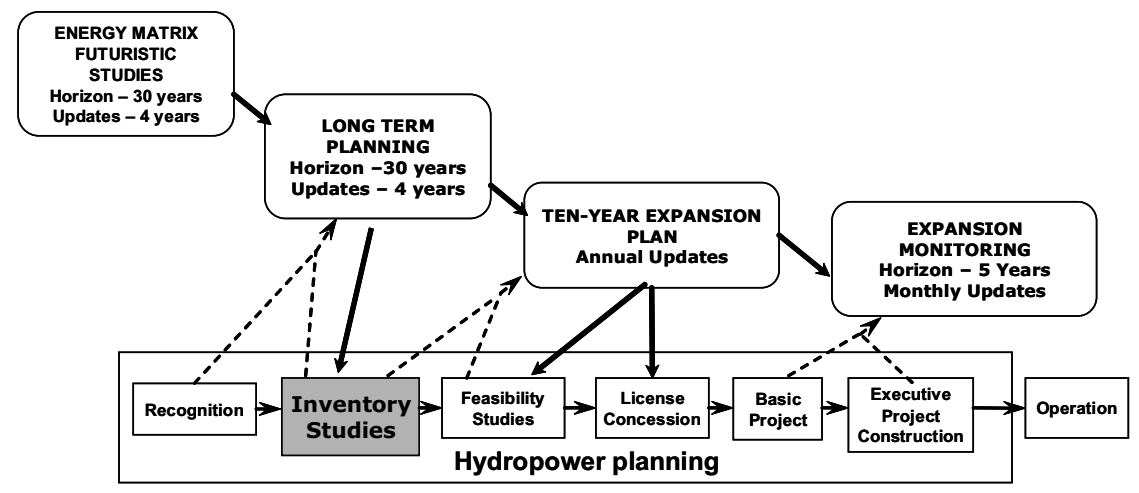

Figure 1: Brazilian National Power System expansion planning and hydropower planning.

The position of the river basin inventory studies in the beginning of the decision-making process of the power system expansion planning gives to these studies a strategic character, as, at this time, the resources are still not committed with the implantation of the future hydropower plants that will compose the river basin head division. Therefore, that is the moment that all the alternatives for the river basin head division should be surveyed and studied to select the one that presents the best efficiency in energetic and socio-environmental terms.

Inventory studies are developed according to the Hydroelectric River Basin Inventory's Manual [2], which criteria and methodologies were recently revised with special focus on socio-environmental and multiple uses of water issues.

To assist hydroelectric inventory studies, a computerized decision support system, named SINV [3, 4], has been developed and it integrates data management with simulation/optimization and plotting tools to aid in energetic and socio-environmental comparisons of the different head division alternatives considering a multi-objective criterion formed by three dimensions: cost of generation, negative and positive socio-environmental impacts. This paper presents a river basin inventory study using the new version of SINV package developed to incorporate the methodologies proposed in the recent inventory's manual. 


\section{Hydropower River Basin Inventory in Brazil}

The Hydropower River Basin Inventory goal is to analyze all the river basin head division schemes and select the best one according to a basic criterion stated as "the maximization of the economical-energetic efficiency with the minimization of the negative socio-environmental impacts, taking into account the positive impacts from the implementation of the hydropower plants in the basin".

The inventory studies are divided into two phases: preliminary studies and final studies. The objective of the preliminary studies is to reduce the number of river basin head division schemes which will be considered in the final studies, when the schemes will be studied with more details and the best one will be selected. The hydropower plants of the scheme selected on the final studies are added to the country inventoried set of hydropower plants and pass to the next stage of the hydroelectric expansion planning studies. The studies in a Hydropower River Basin Inventory can be grouped as: engineering studies, energetic studies, socioenvironmental studies and multiple use of water studies.

\section{Brazilian Hydropower River Basin Inventory Manual - 2007 edition}

The 1997 Manual was a progress, being one of the first efforts for the incorporation of the environmental dimension and the multiple use of water in the energetic studies. In recent years, there was a great progress in the water and environmental subjects in Brazil. The two latest events were: the adoption of the Integrated Environmental Assessment Studies (IEA) as the evaluation parameter for the hydropower plants to be studied in the river basins of the country and the conclusion of Water Resources National Plan (PNRH). So, in the beginning of 2005, the Ministry of Mines and Energy (MME) decided to coordinate the revision process of the criteria and methodologies of the 1997 Manual. The revision was accomplished with the support of a working group formed by different Brazilian entities. The revision introduced several improvements in the hydropower river basin inventories studies, among which we can highlight [5]:

- The adjustment of the methodology for socio-environmental evaluation studies with the methodology of the integrated environmental assessment;

- Development of the methodology for the evaluation of the positive socioenvironmental impacts derived from the hydro plants implementation [6, 7];

- Updating of the spreadsheets/graphics for hydroelectric plants dimensioning and cost quantification;

- Better characterization of multiple water use scenarios upon which the energetic and positive socio-environmental impacts evaluations should be made;

- Introduction of a new multi-objective approach for the final selection of the best head division scheme. 


\section{SINV computational system}

The computational system SINV (River basin Inventory Studies System) is a tool to aid the energetic, socio-environmental and multi-objective analysis studies for selection of the best river basin head division scheme [3, 4]. It follows the criteria and methodologies proposed in the Inventory's Manual.

The last version of SINV system (version 6.0.2) allows:

- The energetic dimensioning of projects. It can be done using three functions: Firm Energy, Storage Capacity Optimization and Energetic Dimensioning. The first one calculates the head division scheme firm energy (the average energy generated during the driest historic period of streamflows) and defines the installed capacity (eqn. (1)) for each plant of the scheme. The second one performs the optimization of the storage volumes of each hydropower plant, considering one head division scheme, with the aim to produce the maximum firm energy. The third one determines at the same time the installed capacity, the storage volume and the reference head for each plant, using an iterative process. In the three functions the energetic parameters can be calculated using simple formulas or a simulation model, which simulates the operation of all plants of the head division scheme. In the preliminary studies it is possible to choose simple formulas or simulation model, but in the final studies the simulation model must be used. The simple formula to calculate the plant firm energy is given by eqn. (2), and the head division firm energy is given by eqn. (3).

$$
\begin{gathered}
P_{i}=E f_{i} / F k \\
E f_{i}=0.0088 \cdot H \operatorname{Hm}_{i} \cdot \operatorname{Qlm}_{i} \quad(\text { in average MW) } \\
E f_{s}=\sum_{i=1}^{n} E f_{i}=0.0088 \cdot \sum_{i=1}^{n} H \operatorname{Hm}_{i} \cdot Q \operatorname{lm}{ }_{i} \quad(\text { in average MW) }
\end{gathered}
$$

where: $\mathrm{Hlm}_{\mathrm{i}}$ - average net head of plant "i” (meters); Qlm $\mathrm{i}$ - hydro plant "i" average net inflow during the critical period $\left(\mathrm{m}^{3} / \mathrm{s}\right) ; 0.0088=1,000 \mathrm{~kg} / \mathrm{m}^{3} \mathrm{x}$ $9.81 \mathrm{~m} / \mathrm{s}^{2} \times 0.93$ (turbine) $\times 0.97$ (generator) $\times 10^{-6} ; \mathrm{Fk}$ - reference capacity factor.

- The economical-energetic feasibility analysis of projects, using the elimination function, which calculates the cost-energetic benefit index (ICB) for each plant. This index is defined by the ratio between the plant cost (installed and operation cost) and firm energy (eqn. (4)). If the plant's ICB is greater than the long term reference energy cost (CUR), then this plant has no economical-energetic feasibility, and must be eliminated from the head division scheme.

$$
I C B_{i}=C T_{i} /\left(8760 \cdot \Delta E f_{i}\right)
$$

where: $\mathrm{CT}_{\mathrm{i}}$ - total annual cost of the plant "i" (R\$/MWh); $\Delta \mathrm{Ef}_{\mathrm{i}}$ - increase of the scheme firm energy when the plant "i" is added to the head division considering all others hydro plants of the scheme already built. 
- The economical-energetic evaluation of head division schemes using the economic-energetic evaluation function. It calculates for each head division schemes its ICB (eqn. (5)) and ranks the schemes by the ICB in crescent order. To be fair, the schemes ICB are calculated considering that the firm energy of all schemes is equal. So, the difference among the maximum firm energy and the firm energy of each scheme is added to each scheme associated with the CUR cost.

$$
I C B_{a}=\frac{C T_{a}+8760 \cdot C U R \cdot\left(E F^{*}-E F_{a}\right)}{8760 \cdot E F^{*}}
$$

where: $\mathrm{CT}_{\mathrm{a}}$ - total annual cost of the head division scheme "a" $(\mathrm{R} \$) ; \mathrm{EF}_{\mathrm{a}}-$ firm energy of the head division scheme "a" (average MW); $\mathrm{EF}^{*}$ - maximum firm energy of the head division schemes (average MW).

- The economical-energetic prioritization of the hydropower plants of the selected river basin head division scheme, using the order function. It is based in hydro plant incremental cost, calculated considering as built all other hydro plant with incremental cost less than the hydro plant in focus.

- The consideration of the multiple uses of the water scenario in the river basin.

- The calculation of negative and positive socio-environmental impacts indexes of the river basin head division scheme, obtained by calculate the negative impacts function and calculate the positive impacts function, respectively.

- The comparison and selection of river basin head division schemes according to the multi-objective analysis, using the preliminary multi-objective function and the final multi-objective function. The first one is used in the preliminary phase, which objective is to select the river basin head division schemes that will be considered in the final studies. To achieve this goal a multi-objective analysis considering the maximization of the economic-energetic efficiency, represented by its ICB (eqn. (5)), with the minimization of the negative socio-environmental impacts is done. The criterion adopted for selecting the schemes to be considered in the final studies is the Optimal Pareto (the schemes for which there are no schemes that present both index smaller than its. They are named Dominant Schemes). The second function is used in the final phase, which goal is to select the scheme that maximizes the economicenergetic efficiency and minimize the negative socio-environmental impact, taking into account the positive socio-environmental impacts. To achieve this objective, first, it is necessary to calculate the Preference Index for each scheme $\left(\mathrm{I}_{\mathrm{A}}\right)$, defined as:

$$
I_{A}=p_{c b} \cdot \frac{I C B_{A}}{C U R}+p_{s e} \cdot I N_{A}
$$

where: $\mathrm{p}_{\mathrm{cb}}+\mathrm{p}_{\mathrm{se}}=1$ and $\mathrm{p}_{\mathrm{cb}}>0$ and $\mathrm{p}_{\mathrm{se}}>0$.

The values of $p_{c b}$ and $p_{s e}$ represent the importance of, respectively, ICB and $\mathrm{IN}_{\mathrm{A}}$. For the schemes final hierarchy an additional analyzes is done. The positive socio-environmental impact indexes $\left(\mathrm{IP}_{\mathrm{A}}\right)$ are included, resulting in a new preference index, named Modified Preference Index, eqn. (7): 


$$
I_{A}^{\prime}=\left(1-p_{\text {sep }}\right) \cdot I_{A}+p_{\text {sep }} \cdot\left(1-I P_{A}\right)
$$

where: $p_{\text {sep }}$ - relative importance of $\operatorname{IP}_{\mathrm{A}}$.

It is important to note that, for the positive impacts index as near its value is to one better is the scheme, on the other hand, the best value for ICB and IN is near to zero. So, we use the complement of IP to calculate the index I'.

- The sensibility analysis with the weights (relative's importance of each dimension, ICB and the indexes of socio-environmental impacts).

The SINV System possesses a Windows graphic interface. The main screen has an area that allows the users to represent in a topological diagram the dam sites and the segments of river of the studied basin, and it facilitates the data storage and the visualization of the results.

\section{Application}

The study case is based on a real inventory study, but as some information was not available it was necessary to make some approximation, in particular about the data related to the positive socio-environmental impacts. The SINV system was used to make the energetic studies, the socio-environmental studies and the multi-objective analysis for selection of the best river basin head division scheme. As the SINV system does not execute the engineering studies (layout definitions, installation cost calculation, etc) it was supposed that these studies were done before.

\subsection{Preliminary studies}

In the preliminary studies 19 dam sites were identified and 26 hydropower plant projects, as shown in Figure 2, resulting in 15 river basin head division schemes. All 26 hydropower plants projects were initially considered with regularization reservoirs.

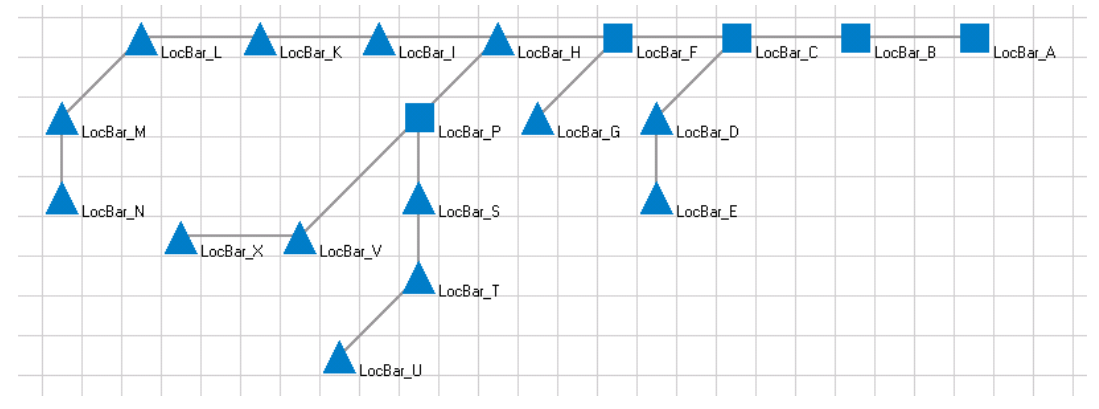

Figure 2: The dam site topological diagram in preliminary studies.

\subsubsection{Energetic studies}

The energetic studies determine the reservoir storage capacities (the regularization capacities), the installed capacities (total generator capacities), and 
the reference heads (net heads in which the turbines with its distributers totally opened will give the installed capacities). For one plant the optimum parameters depends on the head division scheme it belongs. However, one plant could be part of more than one scheme. If the optimum parameters do not change a lot from one scheme to another, we can, by simplification, consider the parameter values that give the greater installed capacity. As mentioned before, in the SINV system, we can use three different functions to determine these parameters: firm energy, storage capacity optimization and energetic dimensioning. As we are in the preliminary studies these functions were executed using simple formulas. As an example, in Table 1 are shown some plants energetic dimensioning in head division Alt_03. We can see that the optimal storage capacity was different from the initial ones for some plants.

After the hydropower plants energetic dimensioning, the next step is to analyze its economical-energetic feasibility using the elimination function. So the hydropower plants ICB were calculated considering the 15 river basin head division schemes. Only the ICB of the $\mathrm{P}_{-} \mathrm{K}$ plant turned out greater than CUR, and this has happened for all head division schemes to which it belongs. But as the difference between its ICB and the CUR was very small, and we were in the preliminary studies, which have several uncertainties, we decided to not exclude this hydro plant from the schemes.

Table 1: Alt_03 scheme energetic dimensioning.

\begin{tabular}{|l|c|c|c|c|c|c|c|}
\hline \multirow{2}{*}{$\begin{array}{c}\text { Hydro } \\
\text { Plant }\end{array}$} & $\begin{array}{c}\text { Maximum } \\
\text { Water level } \\
(\mathrm{m})\end{array}$ & \multicolumn{3}{|c|}{ Before dimensioning } & \multicolumn{3}{c|}{ After dimensioning } \\
\cline { 5 - 8 } & $\begin{array}{c}\text { Min.Water } \\
\text { level } \\
(\mathrm{m})\end{array}$ & $\begin{array}{c}\text { Storage } \\
\text { Capacity } \\
\left(\mathrm{hm}^{3}\right)\end{array}$ & $\begin{array}{c}\text { Ins. } \\
\text { Power } \\
(\mathrm{Mw})\end{array}$ & $\begin{array}{c}\text { Min.Water } \\
\text { level } \\
(\mathrm{m})\end{array}$ & $\begin{array}{c}\text { Storage } \\
\text { Capacity } \\
(\mathrm{hm})^{3}\end{array}$ & $\begin{array}{c}\text { Ins. } \\
\text { Power } \\
(\mathrm{Mw})\end{array}$ \\
\hline P_A1 & 132.00 & 122.50 & 2487.20 & 1620.00 & 129.00 & 1039.20 & 1482.58 \\
\hline P_C1 & 158.00 & 149.40 & 4427.56 & 1218.00 & 155.40 & 1796.60 & 1176.43 \\
\hline P_D1 & 230.00 & 211.70 & 2081.93 & 50.00 & 211.70 & 2081.93 & 48.75 \\
\hline P_G & 220.00 & 204.30 & 4594.30 & 90.00 & 204.30 & 4594.30 & 87.96 \\
\hline P_H & 175.00 & 169.50 & 1017.70 & 656.00 & 171.50 & 680.40 & 600.07 \\
\hline P_I & 212.00 & 199.80 & 4829.68 & 800.00 & 205.33 & 3554.97 & 805.76 \\
\hline P_L & 239.00 & 230.00 & 8129.80 & 500.00 & 230.00 & 8129.80 & 482.87 \\
\hline P_M & 277.00 & 264.70 & 1029.70 & 45.00 & 264.70 & 1029.70 & 40.30 \\
\hline
\end{tabular}

\subsubsection{Socio-environmental studies}

In the preliminary phase, the focus of the socio-environmental studies is on the negative impacts. For calculating this impact index, the environmental system is represented by six synthesis-components: aquatic ecosystem, terrestrial ecosystem, terrain organization, economic base, way of life and indigenous population. With the objective of highlighting the different processes and relationships that occur in the river basin, the basin is divided into subareas for each synthesis-component. For each subarea from one synthesis-component should be given a weight. And each synthesis-component has a weight in the 
environmental system. In this phase the hydro plant socio-environmental negative impacts on each synthesis-component and subarea are analyzed, and a negative socio-environmental impact index is given for each hydro plant. The range of these indexes is $[0,1]$. The value 1 represents the maximum impact and zero represents no impacts. The negative socio-environmental impacts index from one head division scheme $\left(\mathrm{IN}_{\mathrm{A}}\right)$ must represent the cumulative impacts considering all the hydro plants of the scheme, eqn. (8).

$$
I N_{A}=\sum_{c=1}^{n c} I N_{c} \cdot p_{c}
$$

where: $p_{c}$ - the synthesis-component "c" weight in the environmental system; $\mathrm{IN}_{\mathrm{c}}$ - negative socio-environmental impacts index of the scheme on the synthesis-component "c". It is given by eqn. (9).

$$
I N_{c}=\sum_{S A=1}^{N A} I N_{S A}^{c} \cdot p_{S A}^{c}
$$

$\mathrm{P}_{\mathrm{SA}}{ }^{\mathrm{c}}$ - subarea "SA" weight in the synthesis-component "c"; $\mathrm{IN}_{\mathrm{SA}}{ }^{\mathrm{c}}$ - negative socio-environmental impact index of the subarea "SA" on the synthesiscomponent "c", considering the hydro plants of the scheme " $\mathrm{A}$ ".

The negative socio-environmental impacts index for each scheme $\left(\mathrm{IN}_{\mathrm{A}}\right)$ is shown in Table 2, column 6.

\subsubsection{Preliminary multi-objective analysis}

As mentioned before, in this phase, the goal is to reduce the number of schemes, which will be studied with more details in the final phase of the Inventory Study. The preliminary multi-objective function was executed and the results are shown in Table 2. The second column of this table shows the scheme's firm energies, and the third column the firm energies needed in each scheme to reach the

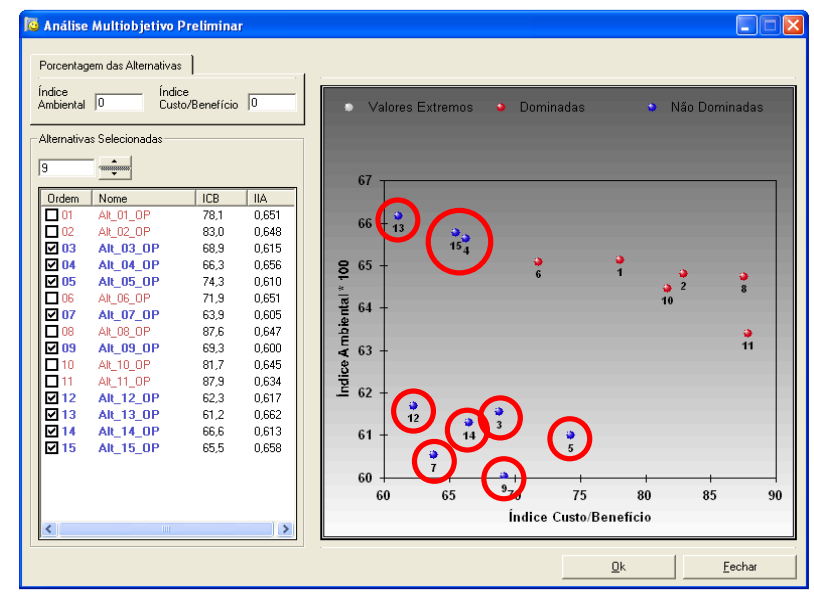

Figure 3: Preliminary multi-objective analysis graphic. 
maximum firm energy in the basin, $3173.25 \mathrm{MW}$, obtained by scheme Alt_13. The column four and five show the scheme's ICB calculated without and with complementation respectively.

Figure 3 shows the multi-objective analysis graphic (the $\mathrm{x}$-axis is the economic-energetic index and the $\mathrm{y}$-axis is the negative socio-environmental impact index), the schemes Alt_13_Op, Alt_12_Op, Alt 07_Op and Alt_09_Op are dominants. If we decide that moving only four schemes to the next phase (final studies) is not enough, it is possible to increase this number including the second Pareto Optimal set of schemes; in this case it was formed by: Alt 03_Op, Alt_14_Op and Alt_15_Op. In this study-case we included the third Pareto Optimal set of schemes: Alt 04_Op and Alt_05, resulting in nine schemes (circulated) that will be moved to the final studies (Table 2, column 7).

Table 2: $\quad$ Scheme selection: Economic-Energetic Index (ICB) and Negative Socio-environmental Impact Index (IN).

\begin{tabular}{|c|c|c|c|c|c|c|}
\hline \multirow{2}{*}{ Scheme } & \multicolumn{2}{|c|}{ Firm Energy (Mw) } & \multirow{2}{*}{$\begin{array}{c}\text { ICB }^{1} \\
\text { (\$/Mwh) }\end{array}$} & \multirow{2}{*}{$\begin{array}{c}\text { ICB }^{2} \\
\text { (\$/Mwh) }\end{array}$} & \multirow{2}{*}{ IN } & \multirow{2}{*}{$\begin{array}{l}\text { Selected } \\
\text { Scheme }\end{array}$} \\
\hline & scheme & Complementary & & & & \\
\hline Alt_13_OP & 3173.25 & 0.00 & 61.17 & 61.17 & 0.662 & YES \\
\hline Alt_12_OP & 3035.67 & 137.59 & 59.11 & 62.31 & 0.617 & YES \\
\hline Alt_07_0P & 3051.70 & 121.55 & 61.11 & 63.87 & 0.605 & YES \\
\hline Alt_15_OP & 3013.35 & 159.91 & 61.96 & 65.54 & 0.658 & YES \\
\hline Alt_04_OP & 3126.03 & 47.22 & 65.31 & 66.32 & 0.656 & YES \\
\hline Alt_14_OP & 2878.12 & 295.14 & 59.77 & 66.58 & 0.613 & YES \\
\hline Alt_03_0P & 2918.09 & 255.16 & 63.24 & 68.85 & 0.615 & YES \\
\hline Alt_09_0P & 2894.69 & 278.56 & 63.15 & 69.28 & 0.600 & YES \\
\hline Alt_06_0P & 2964.84 & 208.42 & 67.61 & 71.91 & 0.651 & NO \\
\hline Alt_05_0P & 2759.25 & 414.00 & 65.54 & 74.34 & 0.610 & YES \\
\hline Alt_01_0P & 3156.51 & 16.74 & 77.85 & 78.14 & 0.651 & NO \\
\hline Alt_10_OP & 3171.26 & 1.99 & 81.69 & 81.72 & 0.645 & NO \\
\hline Alt_02_OP & 2985.16 & 188.10 & 79.83 & 82.99 & 0.648 & NO \\
\hline Alt_08_0P & 2847.98 & 325.27 & 82.41 & 87.59 & 0.647 & NO \\
\hline Alt_11_OP & 2995.72 & 177.54 & 85.23 & 87.91 & 0.634 & NO \\
\hline
\end{tabular}

${ }^{1}$ ICB without considering the complementary firm energy.

${ }^{2} \mathrm{ICB}$ with considering the complementary firm energy.

\subsection{Final studies}

During the final studies, when the number of head division schemes is reduced, the analyses are made with more detail and, if necessary, more information is collected. In this study case, the more detailed analyses identified four new possible dam sites: LocBar_J, LocBar_Q, LocBar_O and LocBar_R. On the other hand, as six schemes were discarded in the preliminary studies, four hydro plants that belong only to these schemes were excluded: $\mathrm{P}_{-} \mathrm{K}, \mathrm{P} \_\mathrm{B} 3, \mathrm{P} \_\mathrm{C} 3$, P F2. 


\subsubsection{Energetic studies revision}

The energetic studies were revised considering the nine river basin head division schemes. The SINV system energetic functions (firm energy, storage capacity optimization, energetic dimensioning) were executed using the simulation model. The energetic dimensioning changed some reservoirs storage capacity. After that, the elimination function was executed. The ICB of the hydro plants $\mathrm{P} \_\mathrm{N}$, P_X (both presented in all schemes), P_Q (in Alt_03 and Alt_05 schemes) and P_O (in Alt_07 and Alt_09 schemes) were greater than CUR, so they were eliminated. The elimination of these hydro plants changed the head division schemes, and then it was necessary to execute the energetic dimensioning again. The new execution of the elimination function showed that the ICB of all hydro plants were smaller than CUR.

\subsubsection{Socio-environmental studies - Negative Impacts Review}

The negative socio-environmental impacts (IN) were revised considering the new information and head division schemes. In this phase, negative impact analysis is done considering the set of hydro plants in the scheme, emphasizing the cumulative and synergetic impacts. The identification, forecasting and evaluation of the negative impacts and the definition of negative impact indexes for each synthesis-component are done for the hydro plant set in each sub-area.

To have a better representation of the cumulative impacts, the indexes values must be given by specialists considering the impact indicators and the evaluation elements selected based on the specificity of the impacting processes. In the SINV system must be specified the criteria and the indicators adopted to give the impacts degree and the socio-environmental impact function calculates for each synthesis-components its impacts and finally the total impact of the scheme, similar to the preliminary studies. Table 3 shows, in column 4 , the negative socio-environmental impact for each scheme.

\subsubsection{Socio-environmental studies - positive impacts}

The positive socio-environmental impact for one scheme on the river basin $\left(\mathrm{IP}_{\mathrm{A}}\right)$, should express the favor changes on the socio-economical development local and regional caused by the set of hydro plants, related on the followed aspects: local labor market dynamization, local government revenues increase, road infrastructure improvement and opportunity for the rationalization of the multiple uses of water [6,7]. The IP indexes are calculated in two phases: first the impact index is calculated taking into account each selected aspect, considering the set of hydro plants in each subarea. After that, the total positive impact index of each scheme $\left(\mathrm{IP}_{\mathrm{A}}\right)$ is calculated by the weighting average of each aspect impact.

The positive socio-environmental impact function gives, for each scheme, the positive socio-environmental impact index associated to each aspect and the total positive index $\left(\mathrm{IP}_{\mathrm{A}}\right)$, shown in Table 3, column 6 .

\subsubsection{Final multi-objective analysis}

In this phase, the goal is to select the best scheme, so, the final multi-objective function is used to rank the river basin head division scheme, according to the 
Preference Index, I, (eqn. (6)) and Modified Preference Index, I',(eqn. (7)). Table 3 presents the I and I' values for the nine schemes. As $p_{\mathrm{cb}}, \mathrm{p}_{\mathrm{se}}$ and $\mathrm{p}_{\mathrm{sep}}$ represent the importance of each dimension, their values must be discussed by a multidisciplinary equip. The Hydroelectric River Basin Inventory Manual says

Table 3: $\quad$ River basin head division schemes hierarchy in final studies.

\begin{tabular}{|c|l|c|c|c|c|c|}
\hline Order & Scheme & ICB/CUR & IN & I & IP & I' \\
\hline 1 & Alt_12_mod_OTF_HF & 0.584 & 0.614 & 0.599 & 0.770 & 0.625 \\
\hline 2 & Alt_14_mod_OTF_HF & 0.625 & 0.609 & 0.617 & 0.750 & 0.637 \\
\hline 3 & Alt_13_mod_OTF_HF & 0.602 & 0.667 & 0.634 & 0.750 & 0.652 \\
\hline 4 & Alt_07_mod_OTF_HF & 0.631 & 0.617 & 0.624 & 0.810 & 0.652 \\
\hline 5 & Alt_15_mod_OTF_HF & 0.644 & 0.658 & 0.651 & 0.730 & 0.663 \\
\hline 6 & Alt_09_mod_OTF_HF & 0.686 & 0.611 & 0.649 & 0.820 & 0.674 \\
\hline 7 & Alt_04_mod_OTF_HF & 0.721 & 0.654 & 0.687 & 0.810 & 0.706 \\
\hline 8 & Alt_03_mod_OTF_HF & 0.761 & 0.620 & 0.691 & 0.840 & 0.713 \\
\hline 9 & Alt_05_mod_OTF_HF & 0.817 & 0.615 & 0.716 & 0.830 & 0.733 \\
\hline
\end{tabular}
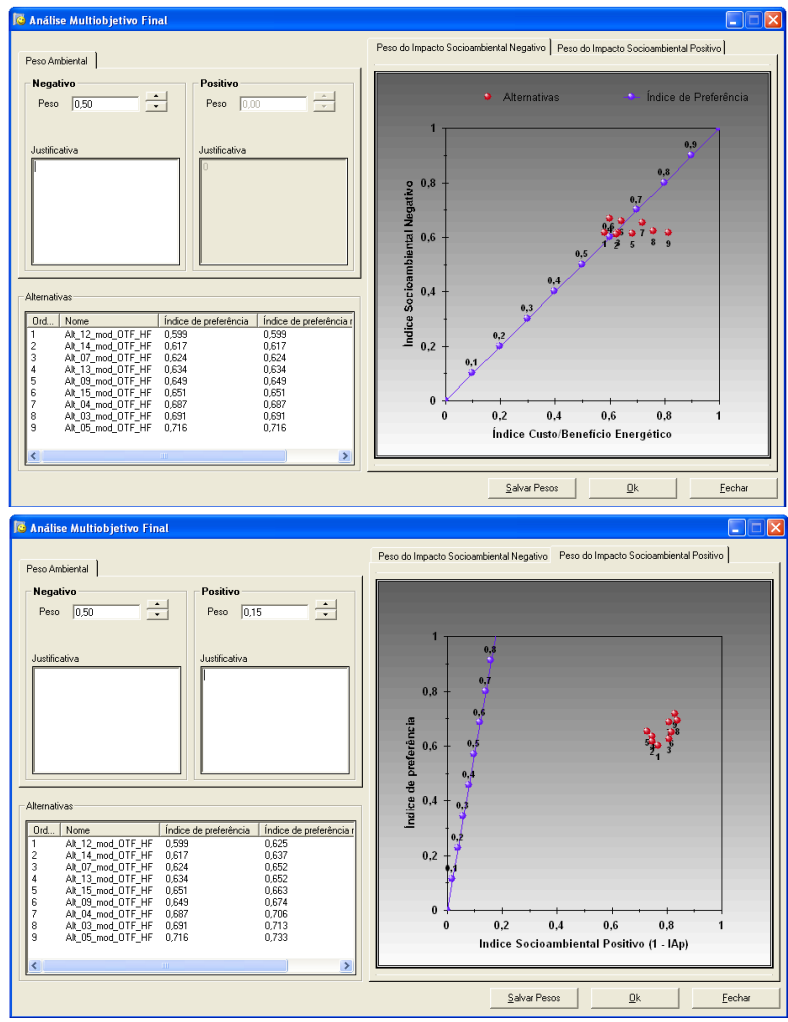

Figure 4: Final multi-objective analysis Graphic (1st and 2nd stages). 
that the positive socio-environmental impact weight must be less than $25 \%$. In this study case we adopted $\mathrm{p}_{\mathrm{se}}=0.5$ and $\mathrm{p}_{\mathrm{sep}}=0.15$. We can see, in this case, that the positive impacts consideration doesn't change the scheme choice. Figure 4 shows the final multi-objective analyses graphics results in both stages, when the index $\mathrm{I}$ is calculated and when the index $\mathrm{I}^{\prime}$ is finally obtained. On the first stage, the $\mathrm{x}$-axis is the economic-energetic index (ICB/CUR) and the y-axis is the IN index, and in the second stage, the $\mathrm{x}$-axis is the positive socio-environmental impact index (IP) and the y-axis is the I index.

\section{Conclusions}

This paper presented the SINV system, a tool to assist the energetic and socioenvironmental studies, as well as the multi-objective analysis for the selection of the best alternative in Hydroelectric Inventory studies in Brazil. A complete study case of an Inventory Study illustrates the SINV system presentation.

This system facilitates the energetic and socio-environmental studies and the selection of the best river basin head division scheme, since the economicenergetic efficiency and the negative and positive socio-environmental impact indexes can be obtained by the same tool, and facilitates the sensitivity analysis as regards the values assigned to each goal (weight), selecting the most robust scheme. The SINV system also facilitates and expedites the analysis of Inventory studies by the entity responsible for its approval, once this tool integrates the three studies. Further more, the adoption of this system facilitates (due to standardization) the storage of information that could be used in the reviews of the inventory studies. It is expected, therefore, that this tool will assist the improvement of the Brazilian expansion planning studies of the Brazilian electric sector.

\section{References}

[1] Maceira, M.E.P., Terry, L.A., Costa, F.S., et al, 2002, "Chain of Optimization Models for Setting the Energy Dispatch and Spot Price in the Brazilian System", XIV Power Systems Computation Conference, Seville.

[2] MME, Manual de Inventário Hidroelétrico de Bacia Hidrográfica, 2007. (In portuguese)

[3] Costa, F.S., Damázio, J. M., Raupp, I.P., 2007, "SINV - Sistema para Estudos Energéticos e Socioambientais de Inventários Hidrelétricos de Bacias Hidrográficas", XIX Eletricity Production and Transmission National Seminar, Rio de Janeiro, Brazil. (In potuguese)

[4] CEPEL, Sistema de Inventário Hidroelétrico de Bacias Hidrográficas SINV 6.0 - Manual de Metodologia, 2008. In: Technical Report DP/DEA 1296/08. (In potuguese)

[5] Costa, F.S., Damázio, J.M., Maceira, M.E.P., Raupp, I.P., et al, 2006, "Inventário Hidroelétrico de Bacias Hidrográficas - Revisão do Manual", X Symposium of Specialists in Electric Operational and Expansion Planning, Florianópolis, Brazil. (In potuguese) 
[6] Damázio, J. M., Pires, S. H., Menezes, P. C., Mollica, A. M., Matos, D.F., Garcia, K., Paz, L.R., 2008, "A Strategic Approach for the Socioenvironmental Dimension in the Hydropower River Basin Inventory”, Revista EletroEvolução, n ${ }^{\circ} 53$.

[7] Pires, S. H., Damázio, J. M., Garcia, K., Matos, D.F., Mollica, A. M., Menezes, P. C., Paz, L.R., 2008, "Evaluation of Cumulative and Synergistic Impacts in the Hydropower River Basin Inventory Studies", IAIA08 Seminar: Assessing and Managing Cumulative Environmental Effects, Calgary, Canada. 